\title{
National Bureau of Standards Mobile Low-level Sounding System
}

\author{
P. D. Lowell, W. Hakkarinen, and D. L. Randall
}

\begin{abstract}
The National Bureau of Standards Mobile Low-level Sounding System is a combination of an improved wiredsonde and an Army SCM-1A mobile weather station. Its purpose is to measure temperature and moisture distributions and their associated gradients and heights from near the ground up to a maximum height of 2,000 feet over different types of terrain. The system has six distinguishing features: 1 . Balloon-level heights can be determined at all times during a flight by data recorded at the ground level by an electric altimeter. 2. Humidity data recorded with this system, which is energized with 60-cycles-per-second alternating current, are reliable for longer periods of time than those obtained by direct-current sounding systems. 3. The system can be operated from within the heated truck body and is suitable for use in dense fog, at night, or during very cold weather. 4. The air-borne unit is of lighter construction because switching and ventilating of the circuit measuring elements are done by a gravity motor instead of a battery-driven motor. 5. The system provides a condition of radio silence during operation. 6 . The system is designed to operate into recorders requiring up to 500 microamperes of direct current. The intelligence from the system can therefore be recorded directly on the equipment in a standard radiosonde receptor installation.
\end{abstract}

\section{Definition and Purpose of Equipment}

The mobile low-level sounding system is a modification of that originally designed by P. D. Lowell and W. Hakkarinen for the Navy Department, Bureau of Ships, in combination with an Army SCM-1A Mobile Meteorological Station [1]. ${ }^{1}$ Its purpose is to measure temperature and moisture distributions and their associated gradients and heights from near the ground up to $2,000 \mathrm{ft}$ over different types of terrain.

p For tropospheric radio-wave propagation measurements, it is desirable to know the vertical gradients of temperature and humidity causing the curvature of transmitted radio energy. Booker [2] has calculated refractive-index gradients in terms of temperature and moisture gradients for a well-mixed layer of air having, at its top, a temperature of $50^{\circ}$ $\mathrm{F}$, a specific humidity of $6.7 \mathrm{~g} / \mathrm{kg}$, and a pressure of $1,015 \mathrm{mb}$. For this layer the critical values that would produce refraction equal to the curvature of the earth are (1) a specific humidity gradient of 0.5 $(\mathrm{g} / \mathrm{kg}) / 100 \mathrm{ft}$, and (2) a temperature gradient of $-5.2^{\circ} \mathrm{F} / 100 \mathrm{ft}$.

Sharp atmospheric refractive-index changes are those that occur in a distance of the order of a wavelength. For radio communication using $100-\mathrm{Mc}$ transmission, this requires measuring the gradients for layers as thin as $10 \mathrm{ft}$, as well as those for thicker layers. Table 1 provides a comparison of the salient features of various meteorological sounding systems in existence prior to the development of the NBS equipment.

Low-level wiredsonde measuring systems are an attempt to combine the mobility and height of the radiosonde measuring system with the fine-grained measurements possible in the tower system. Meteorological sensing elements are supported by a tethered kite, balloon, or kytoon, and the height of

\footnotetext{
1 Figures in brackets indicate the literature references at the end of this paper.
}

the instruments is controlled by reeling the tethered cable in or out. Under calm conditions the balloon height can be regulated to stay at one particular level and the temperature and moisture values of that level studied in detail. The time-lag difficulty of the sensing elements is not so great a handicap in this system as in the radiosonde system because the elements can remain at a given level until they are in equilibrium with the environment.

\section{TABLE 1. Comparison of various meteorological sounding} systems

\begin{tabular}{|c|c|c|c|}
\hline System & $\begin{array}{l}\text { Elements } \\
\text { measured }\end{array}$ & $\begin{array}{l}\text { Sensitivity to } \\
\text { features of air } \\
\text { layer structure }\end{array}$ & Features of system \\
\hline $\begin{array}{l}\text { Radiosonde } \\
\text { (Weather } \\
\text { Bureau } \\
\text { type). }\end{array}$ & $\begin{array}{l}\text { Pressure, tem- } \\
\text { perature, hu- } \\
\text { midity. }\end{array}$ & $\begin{array}{l}\text { Coarse-grained } \\
\text { structure. }\end{array}$ & $\begin{array}{l}\text { Ceiling } 12 \text { to } 18 \mathrm{~km} \text {, } \\
\text { rapid rate of as- } \\
\text { cent, } 50 \% \text { record- } \\
\text { ing of elements, } \\
\text { time lags. }\end{array}$ \\
\hline Tower........ & $\begin{array}{l}\text { Refractive in- } \\
\text { dex, altitude, } \\
\text { temperature, } \\
\text { humidity, and } \\
\text { wind. }\end{array}$ & $\begin{array}{l}\text { Fine-grained } \\
\text { structure. }\end{array}$ & $\begin{array}{l}\text { Ceiling } 50 \text { to } 150 \mathrm{~m} \text {, } \\
\text { continuous rec- } \\
\text { ord, wide selec- } \\
\text { tion of measure- } \\
\text { ments, restricted } \\
\text { location. }\end{array}$ \\
\hline Wiredsonde _. & $\begin{array}{l}\text { Altitude, tem- } \\
\text { perature, hu- } \\
\text { midity. }\end{array}$ & $\begin{array}{l}\text { Medium-grain- } \\
\text { ed structure. }\end{array}$ & $\begin{array}{l}\text { Ceiling } 100 \text { to } 150 \\
\text { m, equilibrium } \\
\text { of sensing ele- } \\
\text { ments with en- } \\
\text { vironment, un- } \\
\text { certainty of } \\
\text { heights. }\end{array}$ \\
\hline
\end{tabular}

\section{Components}

Low-level wiredsonde observations are made with equipment originally designed by P. D. Lowell and W. Hakkarinen. This system consists of an airborne unit, a three-conductor cable, a cable-length controlling reel, an electronic panel, and a recorder. The air-borne unit, which measures pressure, temperature, and humidity, is connected by the threeconductor cable, through a slip-ring contacts on the cable reel to the electronic panel and recorder. 


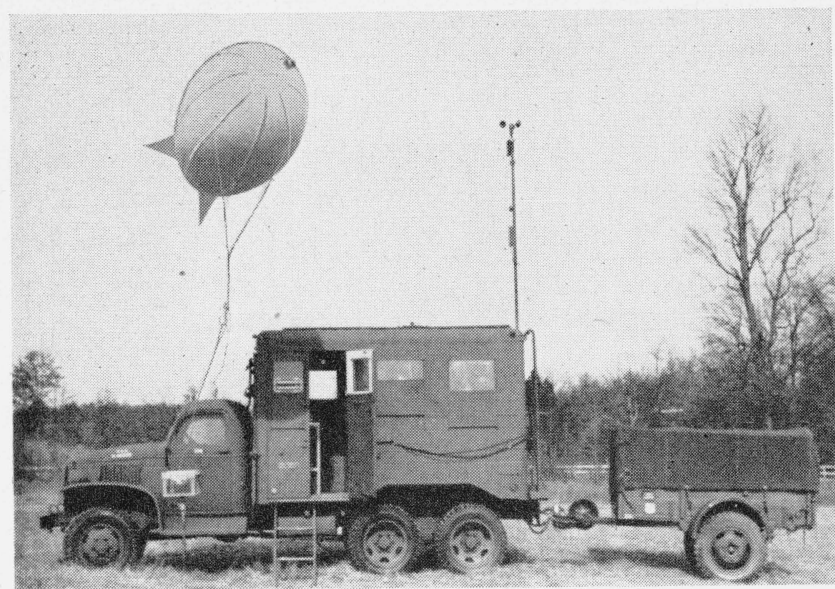

FICURE 1. Low-level sounding truck.

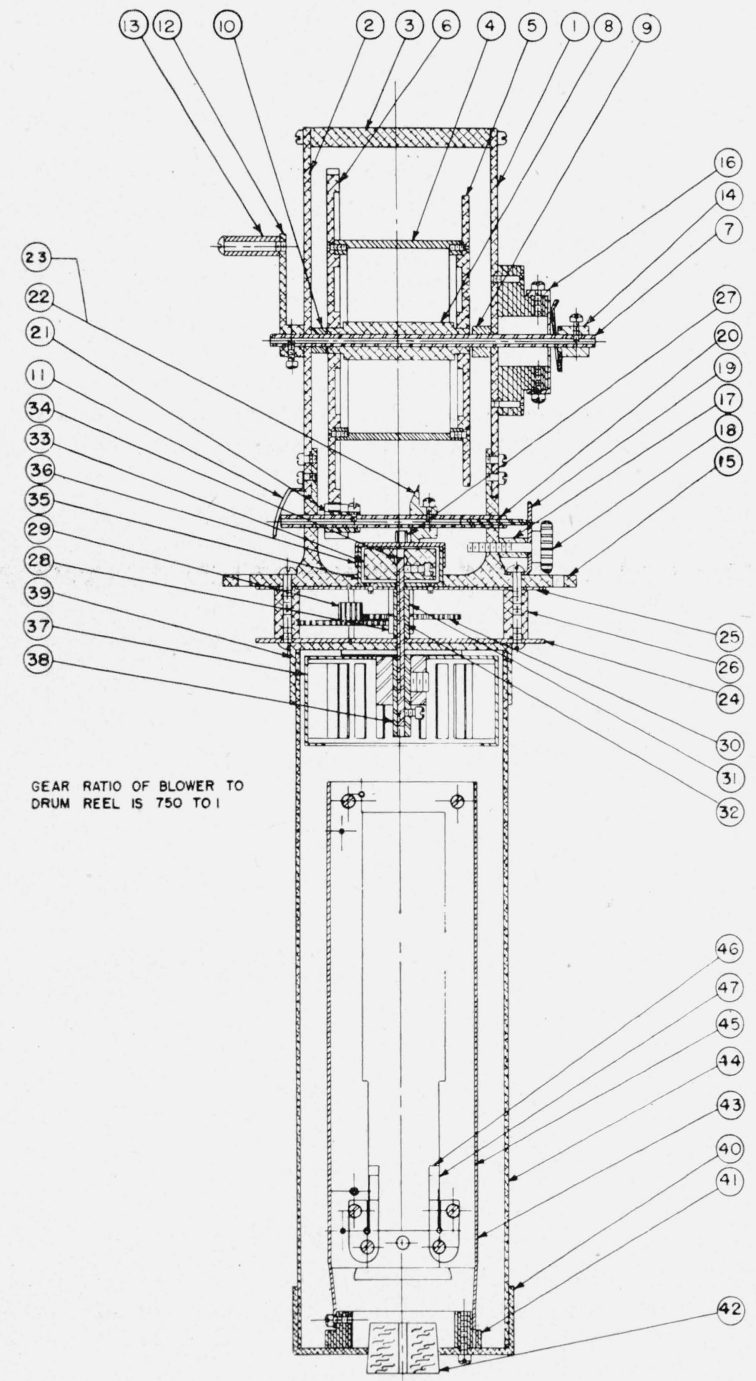

Section $A-A / B-B$
Figure 1 shows a mobile adaptation of the system described herein.

Air-borne-unit support. The air-borne unit is supported by a pair of kytoons or a combination of several $\mathrm{N}-4$ balloons in combination with a $7-\mathrm{ft}$ kite. With the latter combination, it is possible to secure any desired height by adding more balloons, but the combination is not so stable as the arrangement of two kytoons tied side by side in a horizontal plane. The kytoon combination has a free lift of 4 lb in dead calm.

Air-borne unit. The air-borne unit (figs. 2, 3, 4) consists of a gravity motor, an aluminum tube that houses the regular radiosonde temperature and humidity elements, and the pressure-element container clamped to the side of the aluminum tube. At the upper end of the tube, a blower driven by the gravity motor draws air through the tube and expels

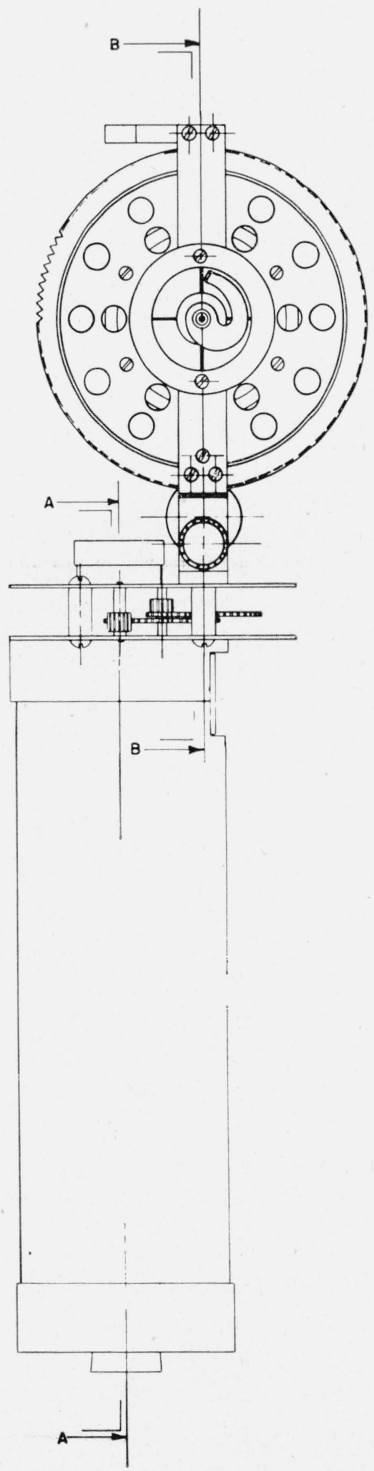

Figure 2. Gravity-motor assembly drawing. 


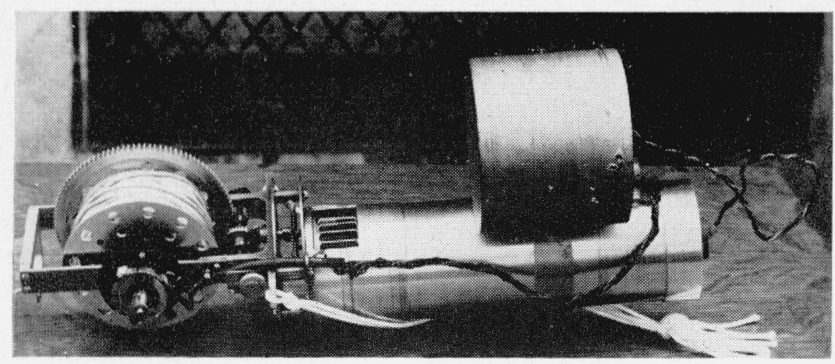

Figure 3. Air-borne equipment.

it through a vent in the side of the blower housing. The gravity motor also switches the pressure, temperature, humidity, and external reference elements into the ground measuring circuit. This motor is driven by the weight of the tethering line and the air-borne instruments suspended from the supporting balloon. A $40-\mathrm{ft}$ length of nylon cord is wound around the drum of the gravity motor and attached to the balloon. The governor on the motor is set so that a tension of $4 \mathrm{lb}$ in the nylon cord drives the blower at about $1,000 \mathrm{rpm}$ and changes the contacts on the commutator switch approximately every $7 \mathrm{sec}$. The governor is efiective in making the blower speed vary directly as the square root of the tension in the cord. A possible application of this relationship is to make gross measurements of the wind speed at the balloon level with respect to the ground. In actual flight tests, it requires about $35 \mathrm{~min}$ for the $40-\mathrm{ft}$ length of cord to become unwound.

The pressure element consists of a berylliumcopper pressure capsule mounted on a rigid castaluminum rectangular frame. The pressure capsule is fastened to the bottom inside center of the frame by a screw connection made through its base. A Mu-metal bar is centered through its face and soldered to the stem of the pressure capsule. This bar completes a magnetic circuit in a U-shaped Mu-metal core, the flux of which is controlled by a coil of about 9,850 turns of No. 40 copper wire. The U-shaped portion of the magnetic circuit is mounted on a duralumin support and is spring-hinged to the castaluminum frame near the coil. The air-gap distance between the Mu-metal bar and the U-shaped magnet is adjusted by two controls - a coarse-threaded machine screw and a finely threaded shaft. These adjustment screws exert pressure against the top and extreme end of the duralumin core support opposite the spring hinge. A thumb wheel on the end of the fine-adjustment shaft is used to make the final settings of the air gap between the Mu-metal plate held by the pressure-capsule stem and the U-shaped core. This thumb wheel is turned against a tight friction bearing for close setting. These two adjustment controls are operated from the top of the aluminum casting. The aluminum casting fits snugly in the pressure-element housing, which is suspended during flight so as to minimize the effects of centrifugal force on the pressure capsule and the Mu-metal plate as the instruments swing about on the line.

The slightest expansion of the pressure capsule

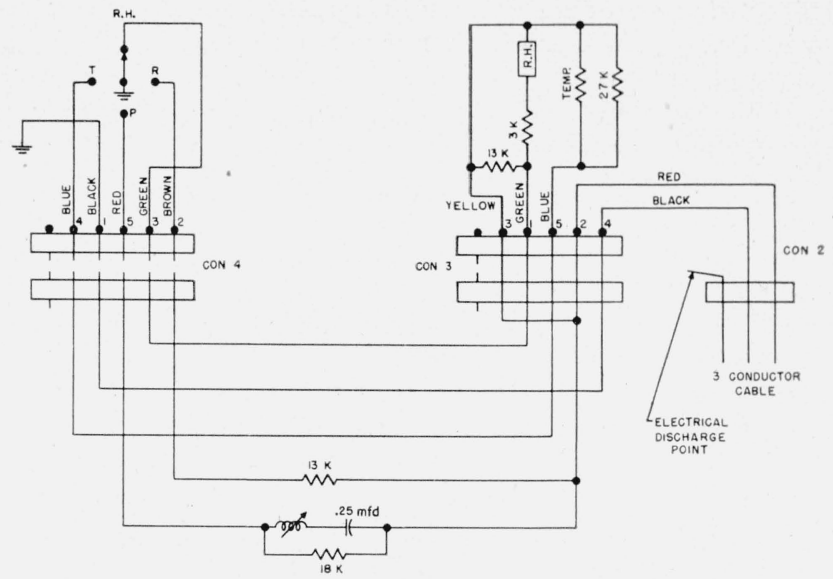

FiguRE 4. Wiring diagram of Air-borne equipment.

with increasing altitude changes the reluctance through the above-described high-permeability magnetic circuit by increasing the air gap over part of the circuit path. Magnetic flux through the highpermeability core and the variable air gap is induced by the above-mentioned coil of wire, which is energized by $60-\mathrm{c} / \mathrm{s}$ alternating current. Thus, the pressure cell, through the varjable air gap in the magnetic circuit, controls the number of lines of magnetic intensity passing through the core of the coil and hence the inductive impedance of the coil as a function of pressure.

Temperature element. The temperature element consists of two radiosonde-type thermistors connected in parallel. These thermistors require 4.4 sec to indicate 63 percent of a sudden temperature change at a ventilation speed of $800 \mathrm{ft} / \mathrm{min}$. The length of one of these rod thermistors is about $1.5 \mathrm{in}$., and its diameter is $0.052 \mathrm{in}$. These thermistors are mounted on a rectangular Bakelite frame that slides through the open end of an aluminum supporting tube. The opposite end of this tube is fitted with an aluminum cap that holds the tube rigidly in the larger 21/2-in.-diameter aluminum tube of the airborne unit. Ventilating holes are provided in the cap and in the end of the internal tube near the cap support. The connecting leads from the frame that supports the thermistors and humidity strip in the internal tube are brought out of the ventilating hole in the cap to a plug receptacle in the top of the pressure-capsule container.

Humidity element [4]. The humidity element is the radiosonde strip hygrometer. This element consists of two spaced conductors supported along the edges of a thin, narrow piece of nonhygroscopic dielectric material. The strip and conductors are covered with a film of polyvinyl alcohol containing lithium chloride.

Three-conductor cable. The three-conductor cable that connects the air-borne unit to the reel, the electronic panel, and to the recorder is made of No. 30 aluminum wire. wrapped around a central nylon strength member. The cable is enclosed in a waterproof nylon cover and has a resistance of 1 megohm/1,000 ft between conductors and a resist- 
ance of $30 \mathrm{ohms} / 1,000 \mathrm{ft}$ along the conductors. The weight of the cable is $2 \mathrm{lb} / 1,000 \mathrm{ft}$ and its tensile strength is $100 \mathrm{lb}$.

Ground pulley. An omni-directional pulley is provided to allow the cable to rise from the ground in any direction (see fig. 5). This pulley is necessary to protect the tethering cable and is usually placed about $100 \mathrm{ft}$ from the truck in a space free from ground obstructions.

Cable-length control. The length of the threeconductor cable is regulated by a motor-driven reel. Slip-ring contacts on the axle of the reel connect the air-borne instruments electrically to the electronic panel. A reversible variable-speed transmission drives the reel shaft through a 30-to-1 worm gear and allows the reel speed to be controlled to a maximum of $60 \mathrm{rpm}$ in either direction. This arrangement eliminates any sudden jerks on the cable, provided that only the transmission is used to start, stop, and reverse the direction of the reel. An automatic-spacing mechanism (level winder) distributes the cable in even layers.

Electronic panel. The electrozic panel (fig. 6) contains an electron-tube circuit that expresses the impedances of pressure, temperature, humidity, and reference elements in terms of direct-current values. The sensing elements are switched into one arm of a voltage-divider network in the grid circuit of a $6 \mathrm{~S} J 7$ tube in a manner so as to prevent the grid current from passing through the sensing elements. The transformer windings for the plate and grid voltages to the $6 \mathrm{SJ} 7$ tube are connected to make these supply voltages 180 degrees out of phase with each other. Thus, with the minimum value of impedance to be measured in the sensing circuit, the bias on the grid is essentially at cut-off for the low plate and screen voltages employed. The entire panel is supplied from a well-regulated source of 60 -c/s power.

Four precision resistor units, two of $1,500 \mathrm{ohms}$ each and two of 3,000 ohms each (R6, R7, R8, and R8A),

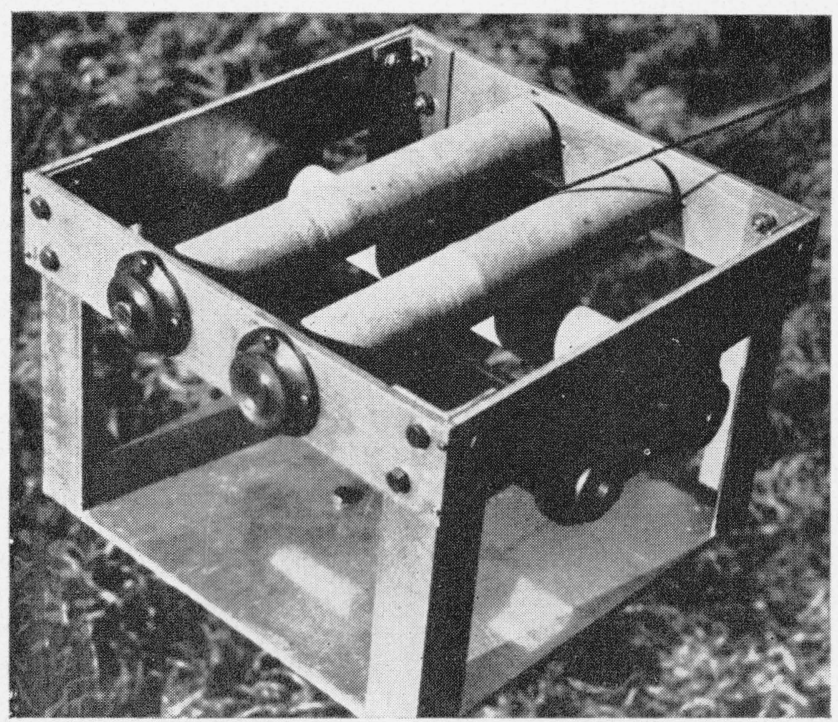

Figure 5. Balloon tethering pulley. connected in series can be inserted in the circuit by $\mathrm{S} 2$ and S5 for calibrating the plate current meter deflections. The recorder-division deflections are 90.0 , $68.0,45.0$, and 6.2 , respectively, on a 100 -unit fulllange chart. These values are obtained by adjusting $\mathrm{R} 3, \mathrm{R} 12$, and R2. $\mathrm{R} 2$ is set to the middle of its range for these calibration-current values. $\mathrm{R} 3$ is a voltage divider for selecting the desired grid potential and is adjusted in conjunction with R 12 (voltage divider for the screen potential) so that tubes having a fairly large variation in transconductance can be used to provide the calibration-current values. Thus the circuit is not critical as to the selection of tubes or to the normal aging effects of them. Having set $\mathrm{R} 3$ and $\mathrm{R} 12$ to get the desired readings, it is generally only necessary to slightly adjust $\mathrm{R} 2$ to set the recorder pen on the reference readings. With 2,000 ft of the three-conductor cable, or the circuit compensated for this length of cable, the external reference in the air borne unit is 79.0 on the recorder scale.

The rectified plate current indicated on the recorder is determined by both the amplitude of the grid-cathode voltage and the phase relationship of that voltage with respect to the instantaneous plate and screen grid voltages. For this reason, the circuit can measure high resistances in the sensing positions at the end of $2,000 \mathrm{ft}$ of cable, although it appears that the shunt capacitative reactance of the cable, approximately 35,000 ohms, would limit the maximum measurable resistance.

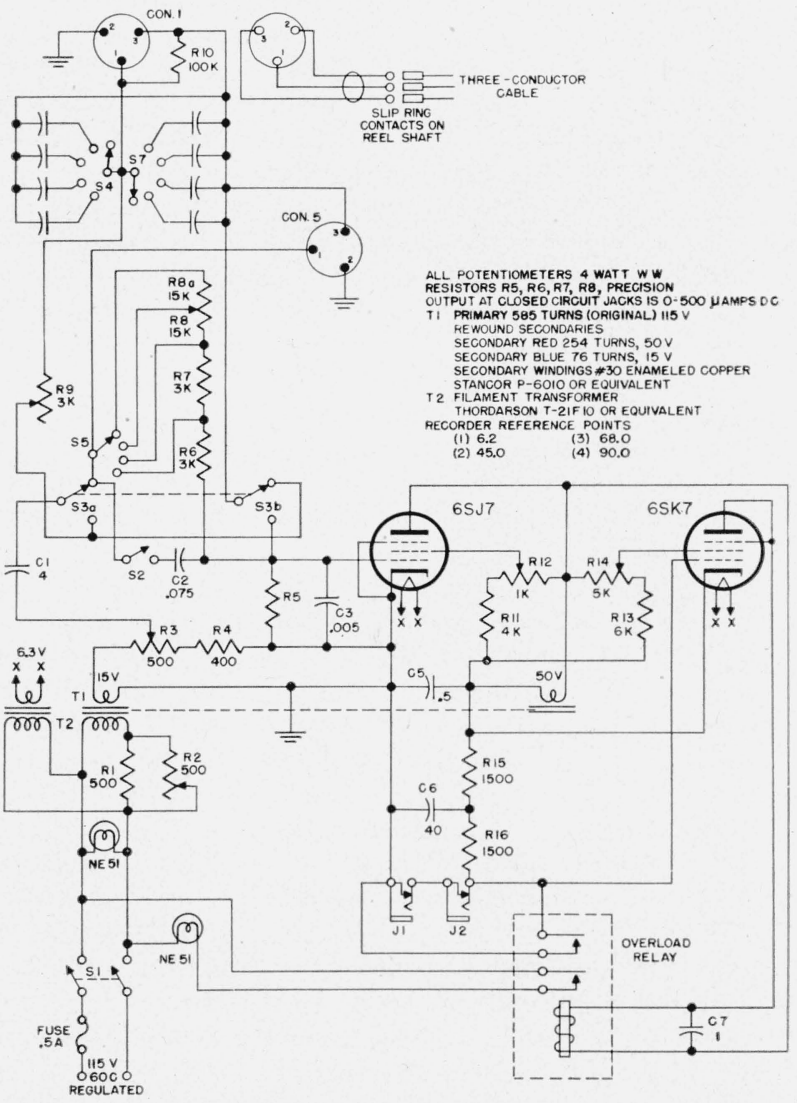

Figure 6. Schematic diagram of the electronic panel. 
The shunt resistors in parallel with the sensing elements are used to limit the measured resistance between 1,500 and 10,000 ohms. This is necessary in order to get sufficient sensitivity in measuring high humidities, which cause the humidity element to have a resistance of about $1,800 \mathrm{ohms}$.

The third wire of the cable is grounded to prevent static charges due to the earth's potential gradient or charged air currents from causing disturbing fluctuations in the measurements. It also serves, in conjunction with its static-discharge point, as a means to keep cloud-induced charges in the cable from building up to lightning-discharge proportions.

The microammeter and the recorder, connected to $\mathrm{J} 1$ and $\mathrm{J} 2$, respectiveiy, are protected against exces sive current by a fast-acting, overload relay circuit. The relay in the plate circuit of the $6 \mathrm{SK} 7$ tube places a direct short across $\mathrm{J} 1$ and $\mathrm{J} 2$ and also operates an overload indicator light when the plate current of the $6 \mathrm{SJ} 7$ tube becomes excessive. The grid bias of the relay control tube is determined by the plate current of the $6 \mathrm{~S} J 7$ flowing through resistors $\mathrm{R} 15$ and R16. The screen grid voltage on the relay control tube is set by an adjustment of R14 so that the relay closes when more than $700 \mu$ a flow through J1 and J2.

Three calibrations are required for operation of the panel with the equipment: the first determines the tube sensitivity, the second locates the reference points for a full 2,000-ft length of cable inserted between connectors 1 and 5 , and the third is performed to obtain these reference points in case of cable breakage.

1. Tube-sensitivity calibration. Switches S3A and $\mathrm{S} 3 \mathrm{~B}$ are set in the internal circuit, or up, position. Switch S2 is closed, placing C2, which simulates the capacity of the cable, in the circuit. The recorderdeflection reference positions $90.0,68.0,45.0$, and 6.2 are obtained when $\mathrm{R} 6, \mathrm{R} 7, \mathrm{R} 8$, and $\mathrm{R} 8 \mathrm{~A}$ are in the circuit. These recorder-deflection values should be repeatable when a constant $115-\mathrm{v}$ current is used to operate the panel. In the case $6 \mathrm{SJ} 7$ tube is changed or becomes aged, R2 and R12 are jointly adjusted until the above reference positions are obtained.

2. Full-length-cable calibration. Insert the 2,000$\mathrm{ft}$ length of cable for which the panel is designed between connectors 1 and 5 . Put $\mathrm{S} 3 \mathrm{~A}$ and $\mathrm{S} 3 \mathrm{~B}$ in the external, or down, position and open S2. Set $\mathrm{R} 9$ and $\mathrm{S} 4$ and $\mathrm{S} 7$ in the minimum position. Insert R6, R7, R8, R8A, and conductor 1 by means of switch S5 between $\mathrm{C} 1$ and R5. Without changing $\mathrm{R} 2$ or $\mathrm{R} 12$ the recorder-reference positions should be approximately the same as those found for the tube-sensitivity calibration. These values should be recorded and referred to for future calibration.

3. Shortened length of cable calibration. Measure the resistance of one conductor of the rejected broken piece of cable, and with an ohmmeter, adjust R9 to a position of twice this value. Insert the shortened length of cable between connectors 1 and 5 . Put S3A and S3B in the external or down position with $\mathrm{S} 2$ open. Insert R6, R7, R8, R8A, R9, and conductor 1 into the circuit between $\mathrm{C} 1$ and $\mathrm{R} 5$ by the switch S5. Without changing R2 or R12, adjust $\mathrm{S} 4$ and $\mathrm{S} 7$ to reproduce the recorded calibration positions obtained in step 2 .

Ventilation in the chamber is provided under all conditions of pressure by a set of 7 -in. fan blades that are driven through a mercury-seal, pressuretight bearing at the bottom of chamber. The bearing shaft is coupled through a flexible rubber hose to a 600-rpm motor. The construction of the mercury-seal bearing is shown in figure 7 .

The humidity box (fig. 8) fits inside the pressure calibration chamber. The mounting frame for the temperature and humidity elements is enclosed in this box. A ring, the same size as the tube on which this frame fits in the airborne unit, holds the temperature and humidity elements about an inch over a tray containing a saturated salt solution (see table 2). A small, motor-driven, centrifugal blower draws air from over the salt solution and blows it onto the bulbs of dry- and wet-bulb thermometers, and thence into the thermistor humidity-strip support. The walls and bottom of the calibration box are made of aluminum, but the top is made of Lucite. The motor is mounted on the outside of the box and is magnetically coupled to drive the ventilating fan.

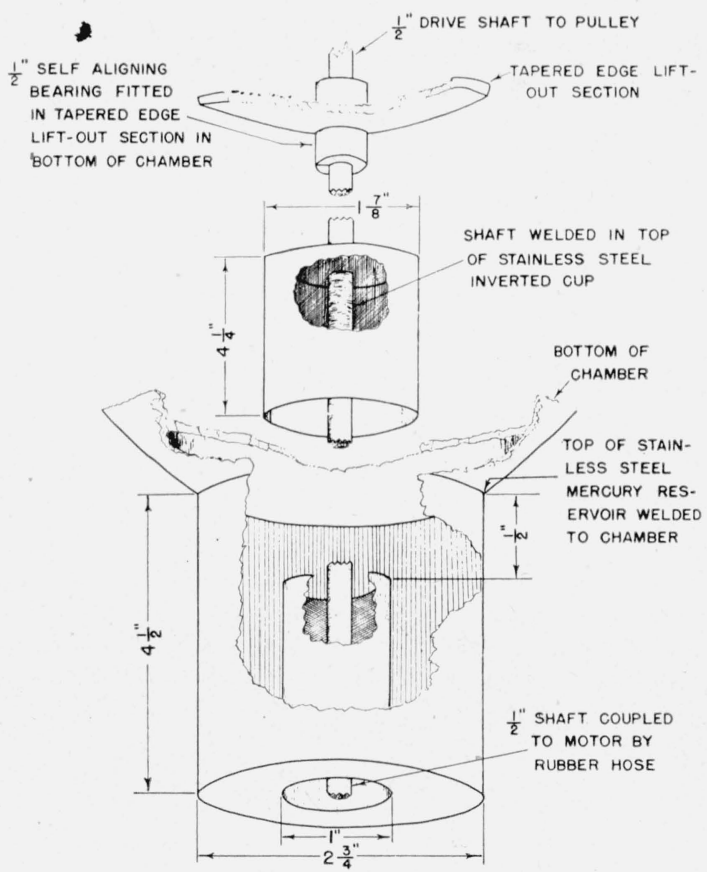

Figure 7. Exploded view of mercury-seal bearing.

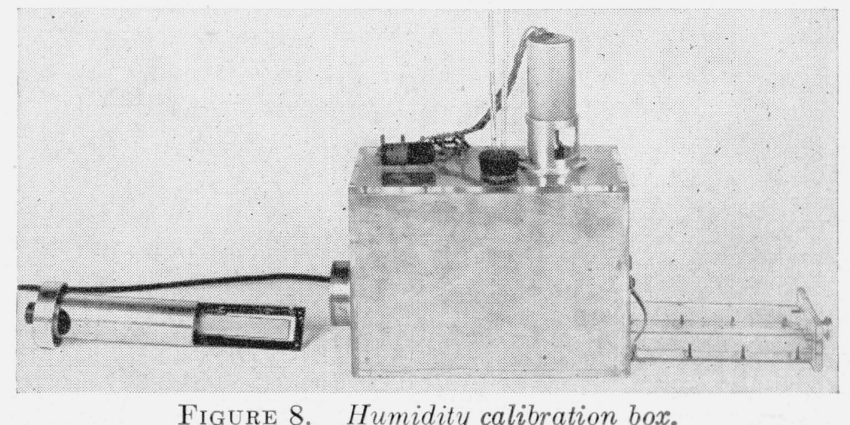

Figure 8. Humidity calibration box. 
TABLE 2. Standard humidity salt brines

\begin{tabular}{|l|c|}
\hline \multicolumn{1}{|c|}{ Chemical } & $\begin{array}{c}\text { Relative } \\
\text { humidity } \\
\text { at } 20^{\circ} \mathrm{C} .\end{array}$ \\
\hline & \\
\hline Potassium nitrate, $\left.(\mathrm{KNO})_{3}\right)$ & 95 \\
Sodium chloride, $(\mathrm{NaCl})$ & 75 \\
Magnesium nitrate, $\left(\mathrm{Mg}\left(\mathrm{NO}_{3}\right) \cdot 6 \mathrm{H}_{2} \mathrm{O}\right)$ & 53 \\
Magnesium chloride, $(\mathrm{MgCl})_{2} \cdot 6 \mathrm{H}_{2} \mathrm{O}$ & 32 \\
Lithium chloride, $(\mathrm{LiCl})$ & 12 \\
\hline
\end{tabular}

The dry- and wet-bulb thermometers are supported through a rubber stopper that plugs into this top. These thermometers are used as a standard measurement of temperature and humidity for the atmosphere of the humidity box.

\section{Calibration Procedures}

\subsection{Pressure}

The altimeter element registers the absolute pressure at the level of the air-borne equipment and is used to measure the difference in pressure between that level and the ground. A calibration curve for measuring these dififerences is constructed from data obtained by calibrating the altimeter in the sealed multipurpose calibration chamber against a precision aneroid barometer.

The air-borne unit is installed in the multipurpose calibration chamber and electrically connected to the three-conductor cable that leads to the reel, electronic panel, and recorder. The altimeter is then adjusted until the recorder reads 70 , corresponding to the ambient or station pressure. Simultaneous readings are then taken of recorder deflection and aneroidbarometer pressures for 3 cycles over the range of 1.010 to $950 \mathrm{mb}$ at 5 -mb intervals.

The calibrations were made so that the difference in the recorder deflections between consecutive 5-mb intervals in the same cycle were obtained over three pressure levels. These sets of recorder-division differences were averaged and used with the corresponding pressure differences. The data given in table 3 were used to construct a calibration curve of pressure dififerences versus recorder-deflection difference (fig. 9).

TABLE 3. Departures from the mean of the individual recorderdivision difference for the indicated pressure levels, as shown by the calibration curve

\begin{tabular}{|c|c|c|c|c|c|c|c|c|c|}
\hline mb. 1,005 & 1,000 & 995 & 990 & 985 & 980 & 975 & 970 & 965 & 960 \\
\hline $\mathrm{mb}$ & 0.1 & 0.1 & 0.2 & 0.1 & 0.1 & 0.2 & 0.2 & 0.2 & 0.2 \\
\hline
\end{tabular}

This curve was considered to hold for all $50-\mathrm{mb}$ intervals from the station pressure (say from 1,020 to 970 or from 1,010 to 960 ) because (1) the altimeter when at the surface was always set to give a recorder deflection of 70 , regardless of the station pressure; (2) these beryllium-copper capsules had linear pressure-expansion curves with a premissible 1-mb deviation, as specified by the manufacturer; and (3) the pressure, recorder-division calibration curve was not effected by temperature changes, as determined by test.

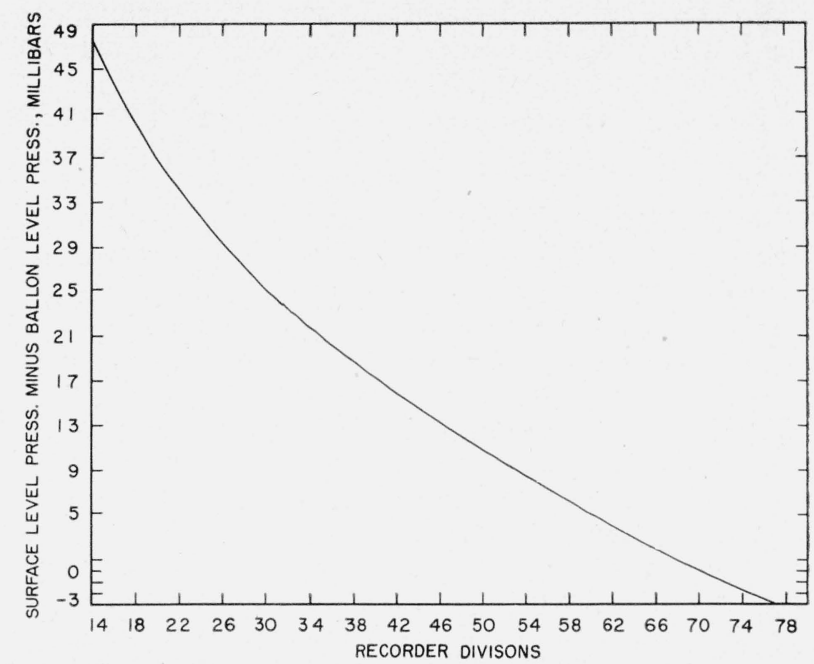

Figure 9. Pressure calibration of the recorder.

As a check on this linearity, a beryllium-copper capsule similar to that used in the altimeter was mounted in a bell jar so that it expanded against the level arm of a dial gage, which was calibrated to read ten-thousandths of an inch and from which it was possible to estimate values of half a ten-thousandth of an inch. A sensitive aneroid barometer, calibrated to $1 / 2-m b$ intervals, was used to measure the pressure inside the evacuated bell jar. Simultaneous readings of the barometer deflection and the capsule expansion were then made every $5 \mathrm{mb}$ over the pressure range 995 to $940 \mathrm{mb}$. A straight line, fitted to the 10 readings thus obtained, showed that the expansion of the capsule was linear insofar as it was possible to measure it.

\subsection{Temperature}

The temperature element is a rod thermistor of the type used in the radiosonde. A convenient way to calibrate this thermistor is to use a Wheatstone bridge, a temperature-controlled oil bath, and an accurate mercurial thermometer. Because the change in temperature of the oil bath takes place very slowly, the Wheatstone bridge can be set for balance at a given resistance position and the temperature read on the thermometer exactly at the time the bridge comes to balance.

Sixty-eight evenly spaced readings were made in this fashion for two complete cycles over the range from $0^{\circ}$ to $40^{\circ} \mathrm{C}$. The temperature values were plotted to hundredths and the resistance values to the nearest ohm, and a smooth curve drawn to fit the greatest number of points. The departures from the curve in degrees centigrade were tabulated from the 68 points, and the average was found to be $0.07 \mathrm{deg} \mathrm{C}$.

The temperature-versus-resistance calibration curve holds throughout the life of a particular thermistor. It is necessary to calibrate each thermistor used in the air-borne unit in this fashion (fig. 10).

To calibrate the recorder, a decade resistance box was connected in place of the rod thermistor in the 


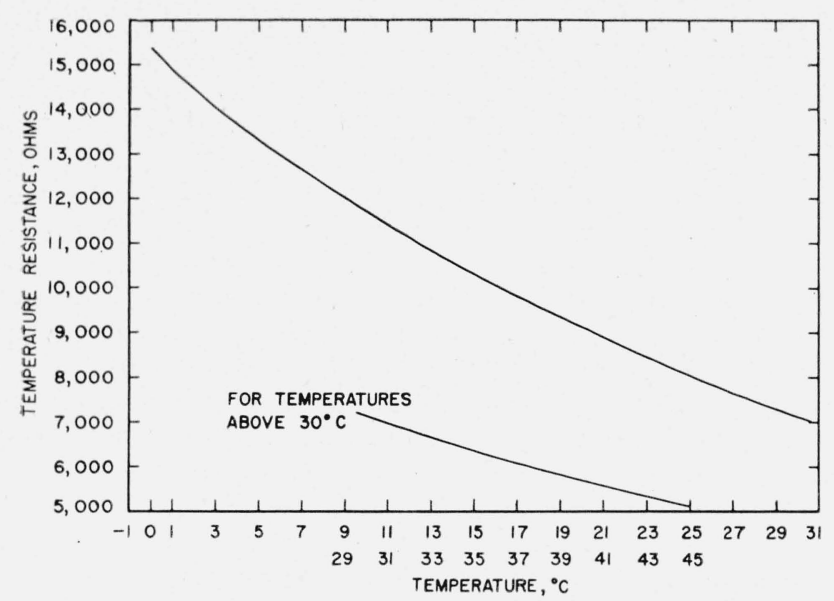

Figure 10. Temperature versus resistance calibration.

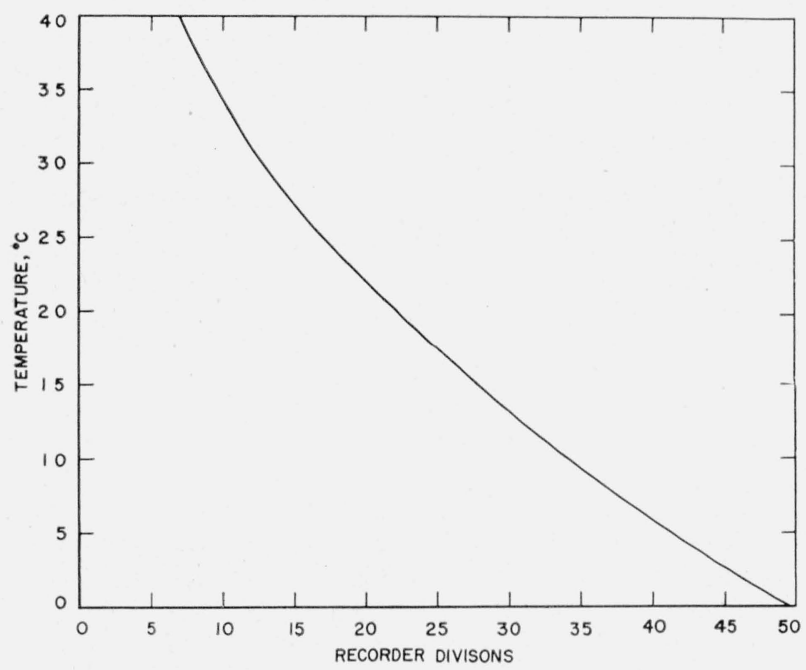

Figure 11. Temperature calibration of the recorder.

air-borne circuit, and a curve of resistance-versusrecorder division was constructed. The temperature versus-resistance calibration curve is used with a resistance-versus-recorder-division curve to construct a direct-reading temperature-versus-recorder-division curve (fig. 11).

\subsection{Humidity}

The humidity element is the standard strip hygrometer used in the radiosonde. The resistance of this element is both a function of temperature and of humidity. The hygrometer is placed in the previously described calibration compartment. The metal walls of the box are coated with a thin oil film so that condensation will be retarded on these surfaces. The box is cooled to the lowest temperature at which observations are to be taken, and a tray containing a saturated salt solution is inserted. After humidity equilibrium has been reached, simultaneous readings are taken of the resistance of the hygrometer strip and of the wet- and drybulb thermometers. The 60-cycle a-c resistance values of the strip are read from the dials of the

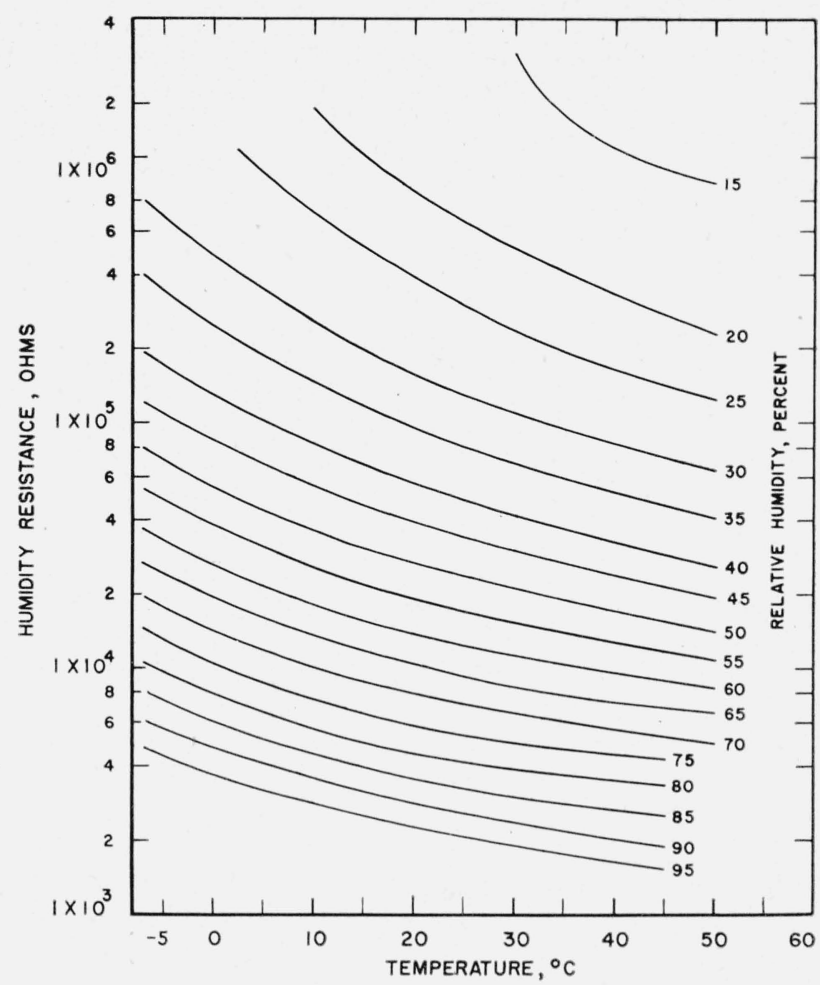

Figure 12. Humidity versus resistance calibration.

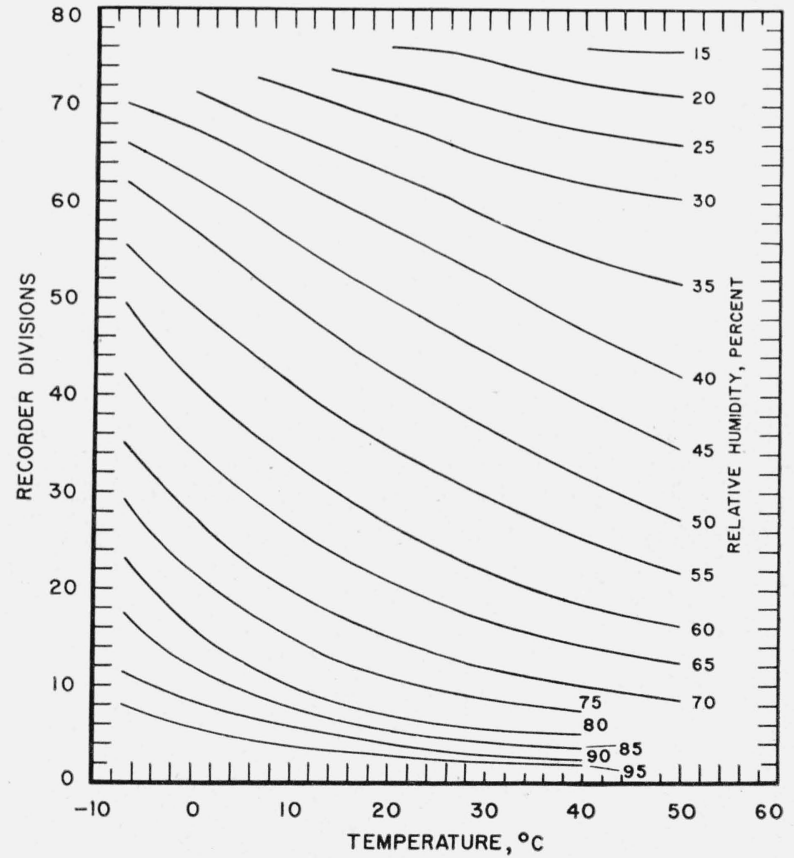

Figure 13. Humidity calibration of the recorder.

Wheatstone bridge, and the humidity percentages are computed from the dry- and wet-bulb temperatures. This procedure is followed for humidity atmospheres of $12,32,53,75$, and 95 percent.

Forty-six points were thus plotted. These values were compared with another, much more extensive, 60 -cycle a-c calibration of the strip hygrometer 
made by another laboratory. These data covered a range from $-10^{\circ}$ to $+40^{\circ} \mathrm{C}$. for humidities from 5 to 95 percent. The logarithims of the resistances were plotted against the temperatures. Curved diagonal lines were drawn across the chart for every five relative-humidity units (fig. 12). Figure 13 is a calibration chart showing relative-humidityversus-recorder divisions.

\section{Flight Computations}

Two types of computations, height and refractivity, are made from the data recorded during a lowlevel sounding flight. Each revolution of the balloonborne gravity-motor commutator gives an indication of a value of pressure, temperature, and humidity on the recorder trace in the truck for a particular point in space. The revolutions of the commutator are numbered on the recorder chart, and these numbers are used to identify the point data taken during a sounding. In an ordinary 40 -min flight there are about 320 such points. The refractivity and height are worked out and tabulated for each of these positions. These points are then plotted on a graph with refractivity values as abscissas and height as ordinates. The work involved in the construction of this graph is simplified by the use of altitude charts. The formulas for these charts follow.

Altitude-computation charts formula. Three altitude-computation charts were prepared to cover the range from 928 to $1,050 \mathrm{mb}$. One of these charts is

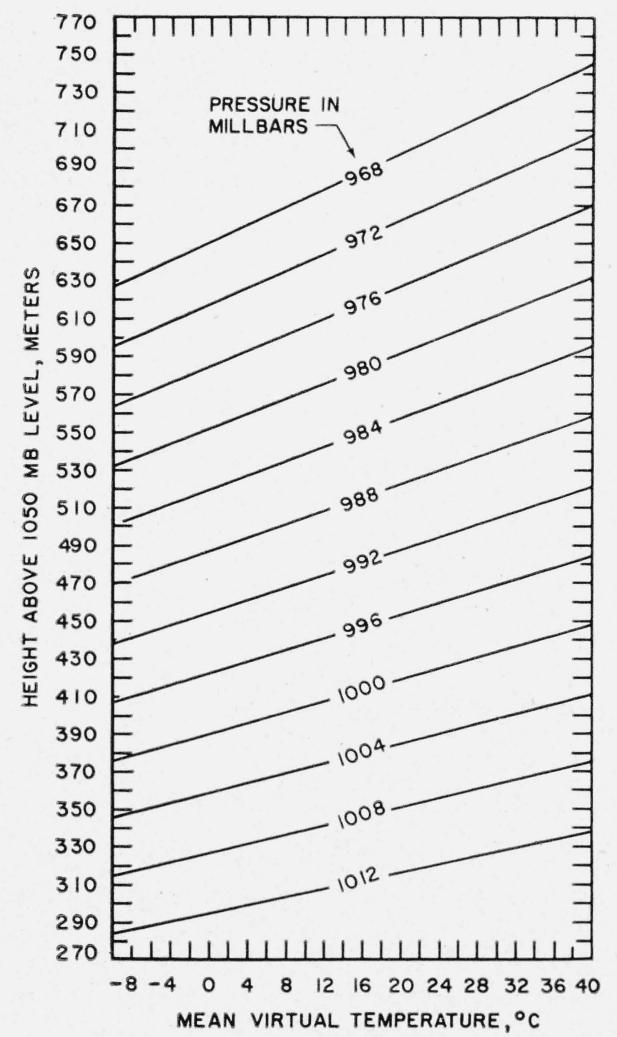

FIGURE 14. Altitude computation chart (968 to $1.012 \mathrm{mb}$.). shown in figure 14. The charts are based on the formula $[6,7]$.

$$
H=67.403 T_{M}^{\prime}(\log 1,050-\log P) .
$$

$H$ is the altitude, in meters, above the $1.050-\mathrm{mb}$ surface; $T_{M}^{\prime}$ is the mean virtual temperature of the layer whose height is measured and is equal to $T_{M}\left[1+0.376(e / p)_{M}\right]$, in which $(e / p)_{M}$ is the mean value of the ratio of the water-vapor pressure to the actual pressure throughout the layer, $T_{M}$ is the actual mean temperature of the layer whose height is measured, and $P$ is the pressure at the level of the surface whose height is measured above the $1,050-\mathrm{mb}$ surface. A table of logarithms to the base 10 is used for substituting these pressure values in the formula.

In practice, over the short height intervals (less than $650 \mathrm{~m}$ ) for which these charts are designed, it is sufficient to use the mean of the balloon-level and surface-level temperature for $T_{M}^{\prime}$.

Refractive-index computation formula. The refractivity of the air, $N$, is computed from the temperature, pressure, and humidity measurements by use of the following formula [10]

$$
\begin{aligned}
N \equiv(n-1) 10^{6}=\frac{77.6}{T}\left(p+4810 \frac{e}{T}\right) & = \\
& \frac{77.6 p}{T}+\frac{3.73 \times 10^{3} e_{s}(R H)}{T^{2}},
\end{aligned}
$$

where $p$ is the total pressure in millibars, $T$ is the absolute temperature in degrees Kelvin, $e$ is the partial pressure of water vapor in millibars, $e_{s}$ is the saturation vapor pressure in millibars, $n$ is the refractive index of the air, and $(R H)$ is the relative himidity in percent. A special slide rule for this computation has been developed by Weintraub [11].

Illustrative examples of flight computations. Figure 15 is a reproduction of a portion of a low-level sounding flight started at 11:50 a. m. on August 31, 1950. As explained previously, the sequences of pressure, relative humidity, and temperature measurements are numbered and tabulated corresponding to the revolutions of the balloon-borne gravity motor (table 4). No corrections are applied to the deflec-

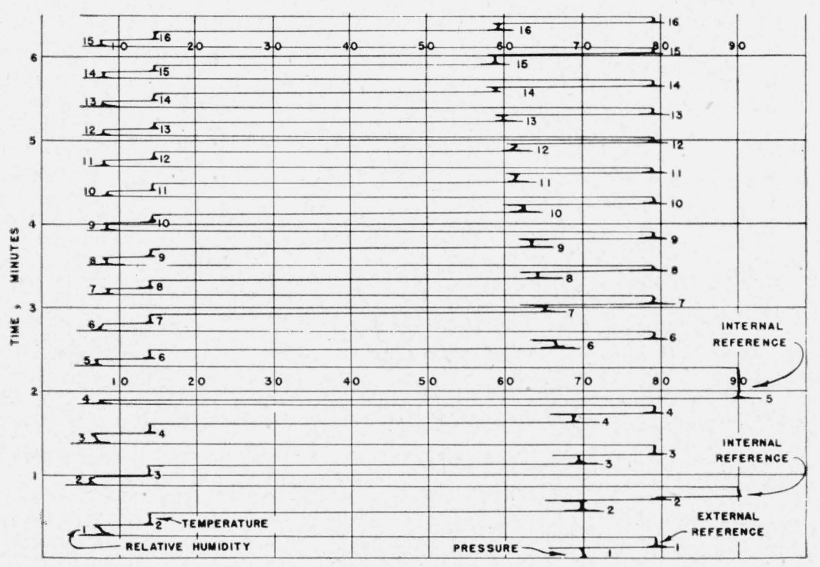

Figure 15. Flight-record sample. 
TABLE 4. Low-level sounding recorder data for the beginning of a flight started at 11:50 a. $\mathrm{m}$.

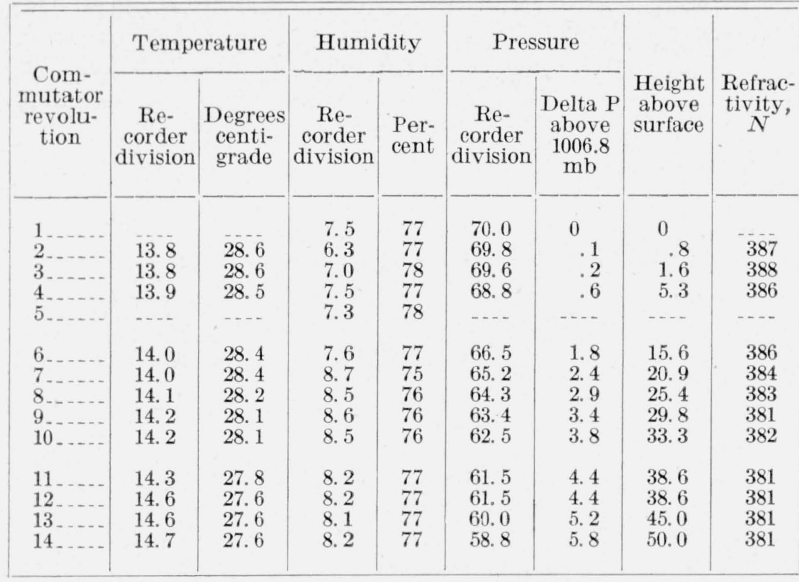

tions because the external reference position remains fixed.

The calibration curves (figs. 9, 11, 13) are used to obtain the temperature, humidity, and pressure values, respectively. The height of the balloon level above the surface is found by using the altitudecomputation chart (fig. 14), and the corresponding refractivity value, $N$, is determined by use of the refractivity formula given above.

Sample balloon-height computation for balloon flight contact No. 14. Given: balloon-level pressure of $1,001.0 \mathrm{mb}$, surface-level pressure of $1,006.8 \mathrm{mb}$, and mean temperature, $(28.6+27.6) / 2$, or $28.1^{\circ} \mathrm{C}$.

Figure 14 gives the height of the balloon above the 1,050 -mb surface for a mean temperature of $28.1^{\circ} \mathrm{C}$ as $421 \mathrm{~m}$ and the height of the ground above the $1,050-\mathrm{mb}$ surface for the same mean temperature as $371 \mathrm{~m}$. The height of the balloon above the ground is $421-371=50 \mathrm{~m}$.

Sample refractivity computation for balloon-flight contact No. 14. Given: Pressure at balloon level is $1,001.0 \mathrm{mb}$, temperature at balloon level is $27.5^{\circ} \mathrm{C}=$ $27.5+273=300.5^{\circ} K$, relative humidity at balloon level is 77 percent, the saturation vapor pressure is $36.71 \mathrm{mb}[12]$.

$$
N=\frac{77.6 \times 1001.0}{300.5}+\frac{3.73 \times 10^{3} \times 36.71 \times 77}{300.5^{2}}=375.3
$$

\section{Results of Checks and Flight Tests}

The humidity and pressure (altitude) calibrations of the system were checked under field-test or calibration-chamber conditions. It was not believed necessary to perform a calibration-chamber check on the temperature calibration of the system because comparisons between the mercurial thermometer and air-borne unit in a well-ventilated instrument shelter showed little difference between two readings, that is, the values checked within $\pm 1 / 2 \operatorname{deg} \mathrm{C}$. The variation in temperatures read from two mercurial thermometers suspended under similar conditions in the shelter was also of this order of magnitude.
Humidity. The humidity check consisted of 101 comparisons of strip-hygrometer and dry- and wetbulb humidity values in the humidity compartment of the multipurpose calibration chamber. Five separate hygrometer strips were used in making these comparisons; the hygrometer strips were taken from a production lot that met a manufacturing tolerance of \pm 5 -percent relative humidity when used in a radiosonde. No attempt was made to estabish a lock-in or check point for any strip in order to get the greatest accuracy from it. The greatest deviation between the observed values was 5 percent. The exposure life of the first strip was $26 \mathrm{hr}$; the second, $72 \mathrm{hr}$; the third, $20 \mathrm{hr}$; the fourth, $4 \mathrm{hr}$; and the fifth strip was still good after $3 \mathrm{hr}$. The first three strips were used for measurements about $6 \mathrm{hr}$ at the beginning of the test and then for about $1 \mathrm{hr}$ at the end. The fourth and fifth strips were used continuously. It is generally believed that the life of a humidity strip is about $1 \mathrm{hr}$, but with the use of $60-\mathrm{c} / \mathrm{s}$ current in the measuring circuit, the life was extended considerably.

The strip hygrometer was placed in an airtight compartment that provided an approximately constant humidity atmosphere. The temperature of this compartment was varied by applying heat or cold to the multipurpose chamber, and the humidity varied by changing the salt solutions in the compartment. The range of humidity covered was from 20 to 94 percent at controlled temperatures of from $-5^{\circ}$ to $+45^{\circ} \mathrm{C}$. The standard deviation of the humidities indicated by the calibration system as compared to the dry-and wet-bulb humidity was 2.2 percent.

Altitude. An extensive test consisting of 40 observations comparing heights measured by the balloon-borne altimeter of the low-level sounding system and those found by double theodolite triangulation was made. For these results, over the range from 0 to $137 \mathrm{~m}$, the combined standard deviations of the two systems was 3.5 percent. ${ }^{2}$ This value was obtained by taking the standard deviation of all 40 of the individual ratios formed by corresponding pairs of height values about unity.

The heights used for checking the altimeter values were measured by two theodolites stationed at the ends of a level $100-\mathrm{m}$ base line. The tethering pulley of the balloon cable was placed $50 \mathrm{~m}$ to the leeward side of the midpoint of the base line. Balloon heights were computed from the altimeter data and by each of the theodolites. The mean of the theodolite heights for each point was compared with the corresponding altimeter value by forming the ratio of altimeter height to mean theodolite height. The standard deviation of these ratio values from unity was computed (table 5).

The check of the altimeter by the double-theodolite method also afforded an opportunity to compare balloon heights determined by the length-of-cableelevation-angle $\left(h_{\mathrm{C}}\right)$, and the double-theodolite-triangulation $\left(h_{\mathrm{T}}\right)$ methods. For this test the tethering

2 The error of measurement appeared to be proportional to height, so that at $100 \mathrm{~m}$ the error of the combined system is $\pm 3.5 \mathrm{~m}$. The error for either system would be, of course, less than this. The separation of the errors due to each of the methods was tried, but the results were not satisfactory. 
pulley to the balloon was located at one of the theodolite stations. Table 6 shows the results of such a comparison.

Although these data are not extensive enough for reliable statistical analysis, the following conclusions

TABLE 5. Comparison of balloon heights measured by the theodolites and the altimeter

\begin{tabular}{|c|c|c|c|c|}
\hline $\begin{array}{l}\text { Number of ob- } \\
\text { servation }\end{array}$ & $\begin{array}{l}h \text { by the- } \\
\text { odolite } \alpha\end{array}$ & $\begin{array}{l}h \text { by the- } \\
\text { odolite } \beta\end{array}$ & $\frac{h_{\alpha}+h_{\beta}}{2}$ & $\begin{array}{l}h \text { by al- } \\
\text { timeter }\end{array}$ \\
\hline $\begin{array}{l}1 \\
2 \\
3 \\
4 \\
5\end{array}$ & $\begin{array}{l}m \\
58.8 \\
59.0 \\
53.9 \\
50.8 \\
50.5\end{array}$ & $\begin{array}{l}m \\
59.6 \\
54.9 \\
57.4 \\
50.6 \\
48.4\end{array}$ & $\begin{array}{l}m \\
59 \\
57 \\
56 \\
51 \\
49\end{array}$ & $\begin{array}{l}m \\
58 \\
55 \\
53 \\
52 \\
54\end{array}$ \\
\hline $\begin{array}{r}6 \\
7 \\
8 \\
9 \\
10\end{array}$ & $\begin{array}{l}52.1 \\
53.6 \\
58.8 \\
55.5 \\
56.9\end{array}$ & $\begin{array}{l}52.7 \\
53.4 \\
57.8 \\
56.4 \\
57.6\end{array}$ & $\begin{array}{l}52 \\
54 \\
58 \\
56 \\
57\end{array}$ & $\begin{array}{l}53 \\
55 \\
60 \\
54 \\
57\end{array}$ \\
\hline $\begin{array}{l}11 \ldots \ldots \\
12 \\
13 \\
14 \\
15\end{array}$ & $\begin{array}{l}78.3 \\
79.2 \\
81.1 \\
82.5 \\
79.3\end{array}$ & $\begin{array}{l}77.3 \\
79.2 \\
81.0 \\
82.0 \\
78.8\end{array}$ & $\begin{array}{l}78 \\
79 \\
81 \\
82 \\
79\end{array}$ & $\begin{array}{l}75 \\
77 \\
77 \\
79 \\
78\end{array}$ \\
\hline $\begin{array}{l}16 \ldots \ldots \\
17 \ldots \ldots \\
18 \ldots \ldots \\
19 \\
20 \ldots\end{array}$ & $\begin{array}{l}80.1 \\
87.9 \\
81.2 \\
76.2 \\
83.5\end{array}$ & $\begin{array}{l}77.6 \\
87.4 \\
81.4 \\
78.2 \\
83.1\end{array}$ & $\begin{array}{l}79 \\
88 \\
81 \\
77 \\
83\end{array}$ & $\begin{array}{l}78 \\
87 \\
82 \\
79 \\
80\end{array}$ \\
\hline $\begin{array}{l}21 \\
22 \\
23 \\
24 \\
25\end{array}$ & $\begin{array}{l}113.6 \\
107.9 \\
108.0 \\
105.6 \\
106.3\end{array}$ & $\begin{array}{l}113.2 \\
110.6 \\
108.7 \\
102.8 \\
105.5\end{array}$ & $\begin{array}{l}113 \\
109 \\
108 \\
104 \\
106\end{array}$ & $\begin{array}{l}110 \\
112 \\
108 \\
104 \\
104\end{array}$ \\
\hline $\begin{array}{l}26 \\
27 \\
28 \\
29 \\
30\end{array}$ & $\begin{array}{l}103.9 \\
109.1 \\
111.2 \\
120.9 \\
114.2\end{array}$ & $\begin{array}{l}103.8 \\
110.2 \\
109.8 \\
113.4 \\
114.0\end{array}$ & $\begin{array}{l}104 \\
110 \\
110 \\
117 \\
114\end{array}$ & $\begin{array}{l}104 \\
110 \\
108 \\
110 \\
110\end{array}$ \\
\hline $\begin{array}{l}31 \\
32 \\
33 \\
34 \\
35 \\
35\end{array}$ & $\begin{array}{l}131.0 \\
131.5 \\
125.2 \\
131.4 \\
130.2\end{array}$ & $\begin{array}{l}129.3 \\
133.9 \\
127.0 \\
131.1 \\
133.6\end{array}$ & $\begin{array}{l}130 \\
133 \\
126 \\
131 \\
132\end{array}$ & $\begin{array}{l}125 \\
128 \\
130 \\
134 \\
134\end{array}$ \\
\hline $\begin{array}{l}36 \\
37 \\
38 \\
39 \\
40_{\ldots} \ldots \ldots \\
\end{array}$ & $\begin{array}{l}134.5 \\
132.5 \\
127.8 \\
137.1 \\
135.7\end{array}$ & $\begin{array}{l}134.6 \\
129.9 \\
130.5 \\
136.4 \\
135.4\end{array}$ & $\begin{array}{l}135 \\
131 \\
129 \\
137 \\
136\end{array}$ & $\begin{array}{l}133 \\
131 \\
133 \\
131 \\
132\end{array}$ \\
\hline
\end{tabular}

TABLE 6. Comparison of balloon heights

Soundings taken at Sterling, Va.

\begin{tabular}{|c|c|c|c|c|c|c|}
\hline \multicolumn{4}{|c|}{$\begin{array}{l}\text { June } 9,1950,1: 30 \text { to } 2: 30 \mathrm{p} . \mathrm{m} \text {. A verage } \\
\text { surface wind speed, } 9 \mathrm{mph}\end{array}$} & \multicolumn{3}{|c|}{$\begin{array}{l}\text { June } 15,1950,12: 30 \text { to } 2: 30 \mathrm{p} . \mathrm{m} \\
\text { Average wind speed (surface) } \\
15 \mathrm{mph}\end{array}$} \\
\hline$h_{T}$ & $h_{C}$ & Delta $h$ & Delta $h$ a & $h_{T}$ & $h_{C}$ & Delta $h$ \\
\hline \multicolumn{4}{|c|}{ Cable length $91 \mathrm{~m}$} & \multicolumn{3}{|c|}{ Cable length $152 \mathrm{~m}$} \\
\hline $\begin{array}{l}77 \\
83 \\
76 \\
67 \\
78\end{array}$ & $\begin{array}{l}84 \\
89 \\
78 \\
70 \\
79\end{array}$ & $\begin{array}{l}7 \\
6 \\
2 \\
3 \\
1\end{array}$ & $\begin{array}{r}11 \\
10 \\
3 \\
5 \\
2\end{array}$ & $\begin{array}{l}115 \\
128 \\
129 \\
118 \\
139 \\
116\end{array}$ & $\begin{array}{l}119 \\
132 \\
138 \\
122 \\
142 \\
120\end{array}$ & $\begin{array}{l}4 \\
4 \\
9 \\
4 \\
3 \\
4 \\
3\end{array}$ \\
\hline \multicolumn{4}{|c|}{ Cable length $152 \mathrm{~m}$} & $\begin{array}{l}127 \\
123\end{array}$ & $\begin{array}{l}130 \\
128\end{array}$ & $\begin{array}{l}3 \\
5\end{array}$ \\
\hline $\begin{array}{r}51 \\
109 \\
126 \\
73 \\
87\end{array}$ & $\begin{array}{r}81 \\
116 \\
126 \\
83 \\
100\end{array}$ & $\begin{array}{r}30 \\
6 \\
0 \\
10 \\
13\end{array}$ & & 120 & 128 & 0 \\
\hline
\end{tabular}

. Weighted by the ratio 152/91 for comparison with 152-m cable length. seem obvious: (1) The height by length-of-cable method is always the same or greater than that by the double-theodolite method. (2) The variation in height determinations between the two systems is greater at low than at high average surface-wind speeds. This is important to remember because sharp temperature and moisture stratification occurs at low wind speeds.

\section{Status and Future Improvements}

The National Bureau of Standards low-level sounding system in its present state of development is a usable system. The altimeter is designed to be accurate within $\pm 50 \mathrm{ft}$, or less, up to heights of $2,000 \mathrm{ft}$. This accuracy can be easily met, and, up to heights of $600 \mathrm{ft}$, double this accuracy can be obtained. The double-theodolite altimeter tests show that at a height of $328 \mathrm{ft}$ the combined error of both systems is $\pm 11 \mathrm{ft}$ and that this error is proportional to the height. This means that the error of the altimeter itself is less than $\pm 11 \mathrm{ft}$. With care and critical adjustment, the altimeter can be initially set to record surface pressure within $\pm 1 / 10 \mathrm{mb}$. Within the first $200 \mathrm{ft}$ above the ground, elevation changes of $6 \mathrm{ft}$ are readily detectable.

The possibilities of future improvement of this system are numerous. It appears that the sensitivity of the system can be further increased by amplifying the grid-circuit signal. This will permit decreasing the current flowing through the sensing elements and make it possible to use quicker responding temperature elements, such as a bead thermistor, which has a 1-sec time lag in zero ventilation. The life of the strip hygrometer for high humidity values should also be further increased by using this decreased current.

The following are some of the other possible applications of this system: (1) To detect the density of fog or smoke by photometric means. A photronictype photocell can be used as a sensing element so that illumination values from total darkness to bright sunlight can be measured over the full range of the recorder scale. (2) To measure wind speed relative to the ground. The switching rate of the gravity motor is a function of line tension as controlled by the force of the wind on the system. (3) To investigate static charges in the lower atmosphere. The use of an electron tube in the panel measuring circuit makes it possible to measure potentials as a function of heights and charged air currents. The effects of these potentials interfered with the measurement of pressure, temperature, and humidity by the system before one of the conductors of the cable was grounded.

In preparing this report, the authors are indebted to many people for assistance and information, but particular acknowledgment is due E. E. King, W. W. Warren, and Leo L. Hughes, for their valuable suggestions and faithful services. 


\section{References}

[1] Mobile Meteorological Station SCM-1, War Department Technical Manual TM 11-2409 (March 29, 1945).

[2] H. G. Booker, Some problems in radio meteorology, Quart. J. Roy. Meteorol. Soc. 74, 331-332 (JulyOctober 1948).

[3] Manual of radiosonde observations (WBAN) Circular P. U. S. Dept. of Commerce, Weather Bureau.

[4] F. W. Dunmore, An electronic hygrometer and its applications to radio meteorography, J. of Research of NBS 20 (June 1935). RP1102.

[5] Arnold Wexler and W. G. Brombacher, Methods of measuring humidity and Testing Hygrometers, NBS Cireular 512 (1951).

[6] Pressure-Altitude Chart (1050-800 mb), U. S. Weather Bureau Form (WB Form 1154A) U. S. Dept. of Commerce, Weather Bureau.
[7] D. L. Randall and M. Shulkin, CRPL 2-1, U. S. Dept of Commerce, NBS, Survey of meteorological instruments used in tropospheric progagation investigations.

[8] M. Shulkin, CRPL 2-2, U. S. Dept. of Commerce, NBS, Average radio ray refraction.

[9] Propagation of radio waves, Summary Technical Report of NDRC, CP 3.

[10] Ernest K. Smith, Jr. and Stanley Weintraub, The Constants in the equation for atmospheric refractive index at radio frequencies, J. Research NBS 50, (1953) RP.

[11] Stanley Weintraub, Slide rule for the computation of the radio refractive index of air, NBS Report (in preparation).

[12] Smithsonian Meteorological Tables, p. 351-53 (1951).

Washington, June 1951 . 